\title{
Hepatitis B and C Virus Infections among Blood Donors in Blood Transfusion Center, Pokhara, Nepal: Seroprevalence and its Associated Risk Factors
}

\author{
Gyanendra Bikram Shah'1, 2, Krishna Gurung ${ }^{1}$, Bharat Prasad Baral'1, Ram Raja Gurung3, \\ Balkrishna Bhattachan ${ }^{4}$ \\ 1Pokhara Bigyan Tatha Prabidhi Campus, Pokhara Nepal \\ ${ }^{2}$ Central Blood Transfusion Service, Nepal Red Cross Society, Pokhara, Nepal \\ ${ }^{3}$ Deurali-Janata Pharmaceutical Pvt. Ltd., Kathmandu, Nepal \\ 4Siddhi Memorial Hospital, Bhaktapur, Nepal
}

\begin{abstract}
Hepatitis B Virus (HBV) and Hepatitis C Virus (HCV) infections lead to chronic diseases and are the most common causes of liver cirrhosis and cancer in developing countries like Nepal. The study is carried out to determine the seroprevalence of HBV and HCV by using a Rapid kit method and Elisa Method to find out its risk factors. The cross-sectional study was done among blood donating people from 16 ${ }^{\text {th }}$ August 2016 to $19^{\text {th }}$ November 2016. Blood donors in Pokhara Valley were screened for anti-HCV antibodies, anti-HBV antibodies using third generation ELISA kits and automated ELISA Processor in serology laboratory at Central Blood Transfusion Service (CBTS) of Nepal Red Cross Society (NRCS) in Pokhara, Nepal. 1777 $(87.2 \%)$ units were male blood donors and 260 (12.6\%) units were female donors out of 2037 participants. Gender wise, the ratio between male and female was 1:0.1. HBV and HCV infection rate in blood donors were detected at $0.7 \%(15 / 2037)$ and $0.5 \%(8 / 2037)$ respectively. HBV infection rate in volunteer blood donor people was $0.7 \%(14 / 1881)$ which was higher than the replacement donors i.e. $0.6 \%$ (1/156). Similarly, in HCV infection rate in volunteer donor were $0.4 \%(8 / 1881)$. HBV infected people are detected higher than the HCV infected people among the blood donors. In addition, there was no significant relationship between positive results of HBV and HCV tests with the gender, age, tattoo, donor type.

Keywords: Blood transfusion, Sera, HCV, HBV, ELISA, Nepal

*Corresponding Author

Email: balkrishna_bhattachan@hotmail.com
\end{abstract}

\section{Introduction}

Hepatitis B virus (HBV) is an enveloped, hepadnaviridae with partially double-stranded DNA [1]. It is one of the cause of potentially lifethreatening liver infection and is a major global health problem. It can cause chronic liver disease and puts people at high risk of death from cirrhosis of the liver and liver cancer [2]. Worldwide, an estimated two billion people have been infected with the Hepatitis B virus and more than 240 million have chronic (long-term) liver infections. In developing countries like Nepal, The highest prevalence of HBV was found in the 6-15 year age group [3]. Common modes of transmission include perinatal, unsafe injection practices, unsafe blood transfusions, and unprotected sexual contact [4].

Hepatitis C virus (HCV) is single-stranded RNA, enveloped flavivirus that causes liver disease [5]. The disease can range in severity from a mild illness lasting for few weeks to a serious, lifethreatening condition that can lead from cirrhosis of the liver to liver cancer. About 170 million people are infected worldwide [6]. HCV is most commonly transmitted through exposure to infectious blood and it may be transmitted through gender with an infected person or sharing of personal items contaminated with infectious blood, but these are less common [7].

This study is conducted among blood donors in Pokhara Valley in order to study the HBV and HCV seroprevalence, among different groups and subgroups of blood donors. The main aim of this study is to determine the seroprevalence of HBV and HCV by Rapid kit and ELISA Method and find out its associated risk factors. Open land route facilitates the biological and virological spread of diseases [8]. So, in the case of HCV and $\mathrm{HBV}$, millions of migrant workers act as a biological transporter. However, documentation of $\mathrm{HCV}$ and $\mathrm{HBV}$ with past infection is frequent 
in person with routine parenteral exposures which indicate that the transmission by this line is prominent. Accidental parenteral exposures such as needle-stick injuries are quite common in patients. Another route of transmission is having tattoos, drug addicts, heterosexual and homosexual gender, liver diseases, and blood transfusion. Perception and awareness level of people has been changed after the jaundice outbreak occurred in Biratnagar during April-July 2014 [9].

\section{Methods and Materials Study Design and setting}

Cross-sectional and descriptive type of study was done. The study sample comprised of 2037 blood donors. Healthy donors included in this study were donating blood in Blood Transfusion Center, Pokhara at mobile health camp organized by Red Cross Society. This study was conducted from 16 ${ }^{\text {th }}$ August to 19th November 2016.

\section{Study Area and Population}

Blood donors were selected according to the criteria of Blood Transfusion Service (BTS) based on the National Guidelines for BTS. The categories of donors that were present in this study were volunteers and replacement who may be the first time or repeated donor. Individuals selected by donor screening criteria as per NRCS' Standard Operating Procedure (SOP) of 2006 AD. Participants were requested to fill a questionnaire form along with written consent were collected. Each donor was given an ID number for later trace out if needed.

Inclusion criteria: Healthy donors were included for blood donation after taking an interview. The detailed inclusion criteria for blood donors are:donor should be in the age group between 18 to 60 years, body weight more than $45 \mathrm{~kg}$ for male and $35 \mathrm{~kg}$ for female, within normal range blood pressure $120 / 80 \mathrm{~mm}$ without medication and Hemoglobin should not be less than $12.6 \mathrm{~g} / \mathrm{ml}$.

Exclusion criteria: Those who are found unhealthy on the interview were excluded for donation. The exclusion criteria for blood donors are:- in the case of a female, menstruating, pregnant and breastfeeding mother are not allowed for donation and Patients taking antibiotics.

\section{Sample collection and processing}

The blood bags were transported from blood donation campaign site to blood bank in igloo box containing ice bars to maintain the temperature near $4^{\circ} \mathrm{C}$. A few drops of blood is used for blood grouping and $5 \mathrm{ml}$ of blood was allowed to clot or centrifuged at 3000 RPM for 2 minutes in a dry screw-capped test tube to separate serum samples to perform the test for $\mathrm{HBV}$ and HCV.

\section{Detection of HBV and HCV by using Rapid kit test}

Collected Sera were subjected for routine mandatory screening for HBsAg and anti-HCV antibodies by enzyme immunoassay-based rapid tests according to the standard protocol described by respective company (Hepacard, J. Mitra and Co., New Delhi, India, and HCV TRIDOT, J. Mitra and Co., New Delhi, India) [10].

\section{Detection of HBV and HCV by using ELISA method}

Sera from blood donors for $\mathrm{HCV}$ were tested against (anti-HCVs) antigen by third generation enzyme-linked immunosorbent assay (ELISA) and for detection of HBV by HBsAg ELISA (HCV TRI-DOT Test, J. Mitra and Co., New Delhi, India; Hepacard, J. Mitra; Genedia HCV ELISA.3.0, Green Cross, Kyunggido, Korea; and Enzygnost HBsAg 5.0, Dade Behring, Marburg, Germany) [11].

\section{Statistical Analysis}

Pearson's Chi-square test was used to determine the significant association of dependable variables. WinPepi software (version 11.65) was used for quantitative data analysis. A p-value < 0.05 was considered to be statistically significant at $95 \% \mathrm{CI}$.

\section{Results}

A total of 2037 blood samples were collected from donors. The blood was screened by Rapid test and ELISA test to detect $\mathrm{HBV}$ and $\mathrm{HCV}$ infection. Gender wise, the ratio between male and female was at 1:0.1. The infection rate of $\mathrm{HBV}$ and HCV in blood donors were detected to be $0.7 \%(15 / 2037)$ and $0.5 \% \quad(8 / 2037)$ respectively (Figure 1). 


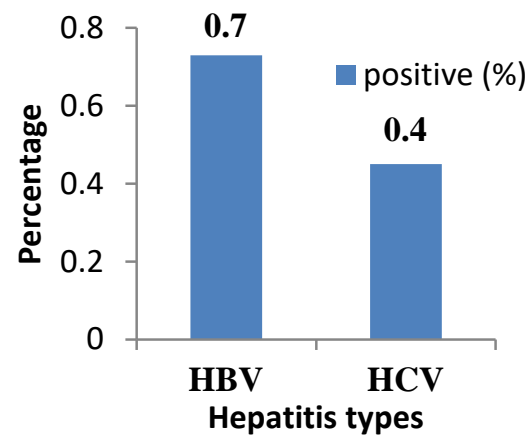

Figure 1: Infection of Hepatitis B Virus and Hepatitis C Virus in blood donors (Confirm by ELISA Method)

The infection rate in a male for $\mathrm{HBV}$ is $0.7 \%$ (13/1777) which was higher than HCV $0.4 \%$ (8/1777). Similarly, the infection rate in the female for $\mathrm{HBV}$ is $0.7 \%(2 / 260)$ which was also higher than $\mathrm{HCV}(0.0 \%)$ but no statistically significant, $(p=0.280)$ result was obtained (Table 1).

Table 1: Sex-wise distribution with Hepatitis diseases among blood donors

\begin{tabular}{lllll}
\hline Gender & Hepatitis & Total No. & $\begin{array}{l}\text { p- } \\
\text { value }\end{array}$ \\
\cline { 2 - 3 } & HBV & HCV & & \\
& No. $(\%)$ & No. $(\%)$ & & \\
\hline Male & $13(0.7)$ & $8(0.4)$ & 1777 & \\
Female & $2(0.7)$ & $0(0.0)$ & 260 & 0.280 \\
Total & $\mathbf{1 5 ( 0 . 7 )}$ & $\mathbf{8 ( 0 . 4 )}$ & $\mathbf{2 0 3 7}$ & \\
\hline
\end{tabular}

In HBV, the highest rate of infection was detected $0.9 \%(7 / 764)$ in $31-45$ year old of blood donors which was followed by $0.7 \%(1 / 138)$ in $46-60$ year old, and $0.6 \%$ (7/1135) in 18-30-year-old people. Similarly, the highest rate of $\mathrm{HCV}$ infection were detected $0.7 \%(1 / 138)$ in $46-60$ years old people followed by $0.6 \%(5 / 764)$ in 31 45 -year-old and $0.2 \%(2 / 1135)$ in $18-30$ years old people, $\mathrm{P}=0.588$, (Figure 2 )

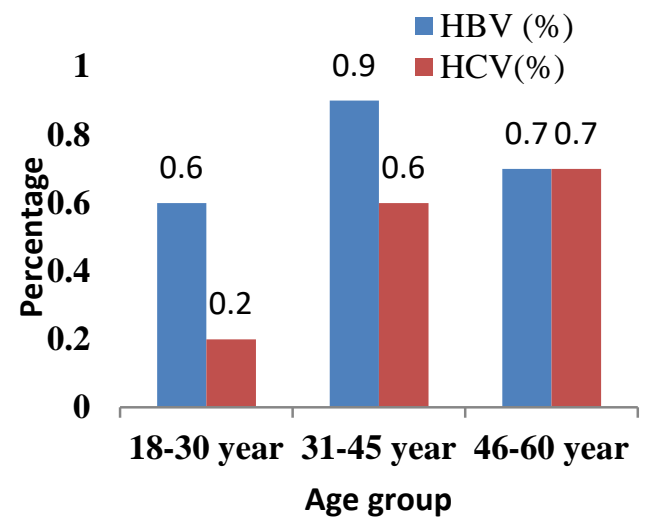

Figure 2. Age wise distribution with $\mathrm{HBV}$ and $\mathrm{HCV}$ among blood donors
HBV infection rate of volunteer donor people was $0.7 \%(14 / 1881)$, which is higher than the replacement donor $0.6 \%(1 / 156)$. Similarly, HCV infection rate of volunteer donor was $0.4 \%$ (8/1881) with $\mathrm{p}=0.455$ (Table 2).

Table 2: Donor type-wise distribution with hepatitis infections among blood donors

\begin{tabular}{lllll}
\hline Donor type & \multicolumn{2}{c}{ Disease } & $\begin{array}{l}\text { Total } \\
\text { No. }\end{array}$ & $\begin{array}{l}\text { p- } \\
\text { value }\end{array}$ \\
\cline { 2 - 5 } & $\begin{array}{l}\text { HBV } \\
\text { No. }(\%)\end{array}$ & $\begin{array}{l}\text { HCV } \\
\text { No. }(\%)\end{array}$ & & \\
\hline $\begin{array}{l}\text { Replacement } \\
\text { Donor }\end{array}$ & $1(0.6)$ & $0(0.0)$ & 156 & 0.455 \\
$\begin{array}{l}\text { Volunteer } \\
\text { Donor }\end{array}$ & $14(0.7)$ & $8(0.4)$ & 1881 & \\
\hline Total & $15(0.7)$ & $8(0.4)$ & 2037 & \\
\hline
\end{tabular}

HBV infection rate in people without tattoo was $0.7 \%(14 / 1847)$ higher than the people with tattoo $0.5 \%(1 / 190)$. Similarly, HCV infection rate in people without tattoo was $0.3 \%(6 / 1847)$ higher than $0.1 \%(2 / 190)$ in people with a tattoo with $\mathrm{p}=0.214$ (Table 3).

Table 3. Tattoo wise distribution with hepatitis infection among blood donors

\begin{tabular}{lccll}
\hline & \multicolumn{2}{c}{ Disease } & & \\
\cline { 2 - 3 } Tattoo & HBV & HCV & Total & p-value \\
used & No. $(\%)$ & No. $(\%)$ & & \\
\hline No & $14(0.7)$ & $6(0.3)$ & 1847 & 0.214 \\
Yes & $1(0.5)$ & $2(0.1)$ & 190 & \\
\hline Total & $\mathbf{1 5 ( 0 . 7 )}$ & $\mathbf{8 ( 0 . 4 )}$ & $\mathbf{2 0 3 7}$ & \\
\hline
\end{tabular}

HBV infection rate of married blood donors was $0.9 \%(12 / 1262)$ whereas $0.3 \%(3 / 775)$ was found in unmarried blood donors. Similarly, $\mathrm{HCV}$ infection rate of married blood donors was $0.7 \%$ $(7 / 1262)$ whereas $0.1 \%(1 / 775)$ was found in unmarried blood donor with $\mathrm{p}=0.65$ (Table 4).

Table 4. Marital status wise distribution with hepatitis infection among blood donors

\begin{tabular}{lllll}
\hline \multirow{2}{*}{$\begin{array}{l}\text { Marital } \\
\text { status }\end{array}$} & HBV & HCV & Total & p-value \\
\cline { 2 - 4 } No & $3(0.3)$ & $1(0.1)$ & 775 & 0.651 \\
Yes & $12(0.9)$ & $7(0.7)$ & 1262 & \\
\hline Total & $15(0.7)$ & $8(0.4)$ & 2037 & \\
\hline
\end{tabular}

Discussion

The group of viruses (Hepatitis A, B, C, D, and E) that cause acute and/or chronic infection and inflammation of the liver give rise to a major public health problem globally [12]. Hepatitis B and $C$ viruses are major agents of severe illness and death. The burden of acute hepatitis, liver 
cirrhosis and cancer due to this Hepatitis B and C Viruses is high worldwide (about $2.7 \%$ of all deaths) and is forecasted to become a higher ranked cause of death over the next two decades. It is estimated that $57.0 \%$ of cases of liver cirrhosis and $78.0 \%$ of cases of primary liver cancer have resulted from hepatitis $\mathrm{B}$ or $\mathrm{C}$ virus infection [13].

The infection rate of $\mathrm{HBV}$ and $\mathrm{HCV}$ in blood donors were detected on $0.7 \%$ and $0.5 \%$ respectively. In the previous study reported that the hepatitis B and hepatitis C infection rate was detected by $2.6 \%$ and $0.3 \%$ respectively out of 307 tested patients [14]. The high percentage of HBV and HCV infection was obtained may be due to less no. of public awareness of hepatitis known infected person did not participated in the blood donation. The unsafe behavioral practices such as body pierce, tattoo, use of injectable drug, unprotected sex etc. also led to increase the transmission of infection. The positive rate of hepatitis infection was found to be higher in a male patient than female but there is no statistical significant relationship found between gender and hepatitis [14]. In HBV infection, most of the infection rate $(0.9 \%)$ was detected in age group ranging 31-45 years old whereas most of the infection rate in 46-60 years old people in HCV was detected at $0.7 \%$. The highest positive rate was found in the patients of age group 31-60 years old [14]. The infection rate of HBV and $\mathrm{HCV}$ in volunteer donor people were found to be $0.7 \%$, and $0.4 \%$ respectively. It may be, due to blood transfusion, hepatitis can be transmitted in another body. Study also revealed that the eastern region of Nepal had the highest percentage of HCV infection (48.0\%) [15]. Seroprevalence of $\mathrm{HBV}$ among mothers were found $17.9 \%$ in 151 mothers of the total study population in the selected Village Development Committees (VDCs) [16]. The highest rates of $\mathrm{HCV}$ and HBV co-infection was found to be $58 \%$ and $70 \%$ respectively $30-39$ years age group.

$\mathrm{HBV}$ infection rate was $0.7 \%$ higher in people without tattoo whereas the HCV infection rate in people without tattoo was $0.3 \%$ higher. Because in our case, the number of participants without tattoo was higher than the number of blood donors with tattoo. Although, it is widely known fact that cosmetic procedure, tattooing on a body can result in a HBV and HCV infection if the needles and equipment used are not properly sanitized. Besides, the poor tattooing procedure may have chances of microbial contamination.

$\mathrm{HBV}$ and $\mathrm{HCV}$ infection rate in married blood donors were $0.9 \%$ and $0.7 \%$ respectively. Researchers concluded the marital status is a significant risk factor [18]. They detected HBV and $\mathrm{HCV}$ were found $1.7 \%$ and $1.0 \%$ respectively in a married participant. HBV and HCV can be transferred from unprotected sexual contact if their partner is infected with the hepatitis virus. People with unsafe sexual relationships and addiction to injectable drug users should always be careful as the chances of the virus getting transmitted are high among them.

This severity of cases may be due to the lack of vaccination information in the population. The replication of $\mathrm{HBV}$ and $\mathrm{HCV}$ in HIV patients should be actively monitored while receiving antiviral therapy and this monitoring system should be made a part of clinical care [17]. In the context of Nepal, people have has less knowledge of vaccination and those who knows avoid it because of hepatitis vaccination cost and no. of clinic visits to complete vaccination doses. The implications of screening tests for HBV or HCV co-infection in HIV patients are of great need in Nepal [18].

\section{Limitations of the study:}

This study was carried out in a limited population and only involved the donors attending on Mobile Health camp organized by BTS-NRS. So, the results obtained from this study might not be enough to indicate the actual burden of the disease in the large population. Still, the study found the existence of endemic viral hepatitis among the people and need health policies to reduce the burden of viral hepatitis in society. PCR based detection method was not incorporated due to feasibility issues regarding time and resources constrain.

\section{Conclusions}

$\mathrm{HBV}$ and $\mathrm{HCV}$ infections can be transfer by piercing needles, general contact, blood 
transfusion, drug users. Therefore, policymaker should provide awareness and knowledge for people about it. General people must take a hepatitis vaccine. Government should provide hepatitis vaccine at an affordable price. Government and its allied body should provide infection control support. Finally, people should be aware of its associated risk factors. The infection rate in prior blood transfusion people, $\mathrm{HBV}$ and $\mathrm{HCV}$ infections found in the same ratio. Moreover, due to its risk factors, like age, gender, tattoo, marital status, donor type can be transmitted the vital role in the mode of transmission of hepatitis.

\section{Conflict of Interest}

The authors declare that they have no competing interests.

\section{Acknowledgments}

We would like to convey our gratitude to Mr. Dhrubamadi Lamichhane, coordinator of Central Blood Transfusion Service and all the members of NRCS (CBTS) who were helpful and made my lab work possible. And, thankfulness to Mr. Arjun Gyawali and allied staffs. Without their support, we could not able to conduct this study.

\section{Consent for publication}

Not applicable

\section{Ethical approval and consent to the participant}

No patient-related data were collected. Ethical approval was therefore not required. The study was laboratory-based basic science study. Written informed consent was taken from all participating patients or from guardian on the behalf of their children.

\section{Availability of data and materials}

All supplementary files, data generated and analyzed during this study will be made available as per reasonable request to the corresponding author.

\section{Source of Support}

No funding

\section{Author's Contributions}

GBS and KG designed the study. GBS collected sample at NRCS-CBTS. GBS and BPB performed investigation and recorded the laboratory findings with the validation. KG supervised and provided a methodology for the study. BPB, BB \& RRG administered the project, reviewed literature, and wrote original manuscript BB and RRG curated data to perform statistical data analysis and data interpretation. RRG \& BB also reviewed, proofread, and revision of the draft by compiling, formatting, editing and writing the final version of the article. Thus, all authors made a substantial contribution to the study. All of them read and approved the final manuscript.

\section{References}

1. Brooks G, Carroll KC, Butel J, and Morse S: Jawetz Melnick \& Adelberg's Medical Microbiology (26 ed. $^{\text {th }} 2012$ USA: McgrawHill.

2. Jindal A, Kumar $M$, and Sarin SK: Management of acute hepatitis $B$ and reactivation of hepatitis B. Liver international. Official journal of the International Association for the Study of the Liver 201333 (Suppl 1):164-175.

3. Shrestha SM, and Shrestha S: Chronic hepatitis B in Nepal: an Asian country with a low prevalence of HBV infection. Trop Gastroenterol. 2012 33:95-101.

4. WHO (2013). Hepatitis, (access on www.who.int/topics/hepatitis/factsheets/en $L)$

5. Younossi ZM, Stepanova M, Mishra A, Venkatesan C, Henry L, Hunt S: The impact of chronic hepatitis $C$ on resource utilization and inpatient mortality for Medicare beneficiaries between 2005 and 2010 . Alimentary pharmacology \& therapeutics, 2013 38(9): 1065-1075.

6. Mullis CE, Laeyendecker O, Reynolds SJ, Ocama P, Quinn J, Boaz I, et al: High frequency of false positive HCV ELISA in Rakai, Uganda. Clinical infectious diseases, An official publication of the Infectious Diseases Society of America, 2013 57(12):1747-1750).

7. Rudra S, Chakrabarty P, Hossain MA, Akhter $\mathrm{H}$, and Bhuiyan MR: Seroprevalence of Hepatitis B, Hepatitis C, HIV Infections in Blood Donors of Khulna, Bangladesh. Mymensingh Medical Journal 2010 19(4) :515-519.

8. Nepal A. and Kunwar B: Evidence of Hepatitis C Virus Infection and Associated Treatment in Nepal. J Mol Biomark Diag, 20167 (270):1-4. DOI: 10.4172/2155-9929.1000270

9. Subba NR: Managing Hepatitis Outbreak in Biratnagar Nepal. Science Journal of Public 
Health, 2015 3(6): 808-814. doi: 10.11648/j.sjph. 20150306.12

10. Tiwari BR., Ghimire P, Kandel SR, and Rajkarnikar M: Seroprevalence of $\mathrm{HBV}$ and HCV in blood donors: A study from regional blood transfusion services of Nepal._Asian J

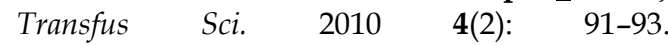
DOI: $10.4103 / 0973-6247.67026$

11. Karki S, Ghimire P, Tiwari BR, \& Rajkarnikar M: HBsAg Serosurveillance among Nepalese Blood Donors. Ann Trop Med Public Health. 2008 11(1):15-18.

12. Gaze R. de, Carvalho DM, Santoro-Lopes G, Tura LF: From Hepatic Diseases and Jaundice to Viral Hepatitis: The Configuration of a Kaleidoscope. Revista de saude publica, 2013 47(1): 116-122.

13. WHO: (2013). Immunization, Vaccines, and Biologicals,

https://www.who.int/immunization/en/

14. Pokheral N, Bhandari D, and Jha B: The pattern of hepatitis $B$ and $C$ infections among patients attending a tertiary care hospital in Kathmandu, Nepal. J Inst Med, 2016 38(2):2-3.

15. Ionita G, Malviya A, Rajbhandari R, William Schluter W Sharma G, Kakchapati RS, and Dixit S: Seroprevalence of Hepatitis B Virus and Hepatitis C Virus Co-infection Among People Living with HIV/AIDS Visiting Antiretroviral Therapy Centers in Nepal: A First Nationally representative study. Intl J Infect Dis. 2017 60: 64-69.

16. Shedain PR, Devkota MD, Banjara MR, Ling H, Dhital S: Prevalence and risk factors of hepatitis $B$ infection among mothers and children with hepatitis $B$ infected mother in upper Dolpa, Nepal. BMC infectious diseases 2017 17(1): 667. doi:10.1186/s12879-017-2763-4.

17. Chuang WL, Dai CY, Chang WY, Lee LP, Lin $\mathrm{ZY}$, Chen SC: Viral interaction and responses in chronic hepatitis $C$ and $B$ co-infected patients with interferon-alpha plus ribavirin combination therapy. Antivir Ther, 2005 10, 125-133. PMid: 15751770 